\title{
Um método para identificação e análise de competências e recursos estratégicos das operações de serviços
}

\section{A method for the identification and analysis of competencies and strategic resources in service operations}

\author{
Luciano Costa Santos ${ }^{1}$ \\ Cláudia Fabiana Gohr ${ }^{1}$ \\ Gregorio Varvakis ${ }^{2}$
}

\begin{abstract}
Resumo: A identificação e a análise de competências e recursos das operações é uma atividade que tem sido frequentemente negligenciada no processo de formulação da estratégia de produção. Reconhecendo a importância dessa atividade, este artigo apresenta uma metodologia que se propõe a incorporar a visão baseada em recursos na estratégia de operações de serviços. Para verificar sua aplicabilidade, a metodologia proposta foi testada em uma academia de ginástica, um típico sistema de operações de serviços que apresenta recursos e processos peculiares. A pesquisa de campo ocorreu segundo a abordagem da pesquisa-ação, na qual um dos autores deste artigo exerceu o papel de facilitador no processo de intervenção organizacional. Os resultados da aplicação sinalizaram para os gerentes da academia os recursos e as competências que deveriam ser priorizados para a manutenção da vantagem competitiva da empresa. Por outro lado, ficou claro para os pesquisadores que o modelo proposto era factível, fácil de usar e útil, além de cumprir seu papel de integrar a visão orientada pelo mercado com a visão baseada em recursos no complexo processo de formulação da estratégia de operações.
\end{abstract}

Palavras-chave: Competências e recursos. Estratégia de operações. Operações de serviços.

\begin{abstract}
The identification and analysis of competencies and resources in operations is an activity that has often been neglected in the process of operations strategy formulation. Recognizing the importance of this activity, this study presents a methodology that aims to incorporate the resource-based view in the service operations strategy. To verify its applicability, the proposed methodology was tested in a fitness center, a service operations system with specific resources and processes. The fieldwork was applied according to the action research approach, in which one of the authors of this paper played the role of facilitator in the process of organizational intervention. The results showed the managers the resources and the competencies that should be prioritized to maintain its competitive advantage. On the other hand, it became clear to the researchers that the proposed model was feasible, useful, and easy to use, in addition to fulfilling its role of integrating the market-oriented view with the resource-based view in the complex process of operations strategy formulation.
\end{abstract}

Keywords: Competencies and resources. Operations strategy. Service operations.

\section{Introdução}

A definição da estratégia de operações de uma empresa é um tópico que tem estado cada vez mais presente na agenda dos gerentes de produção. A importância desse assunto se deve ao fato de que todas as decisões gerenciais relativas à produção estão (ou deveriam estar) diretamente relacionadas com a estratégia competitiva da organização. Assim, a estratégia de operações atuaria como um elo entre a estratégia competitiva e a gestão do sistema de produção (SKINNER, 2007). Embora esse vínculo seja muitas vezes negligenciado nas empresas, no meio acadêmico predomina o pensamento de que a forma pela qual as operações são gerenciadas no dia a dia depende do direcionamento estratégico do sistema de produção (SLACK; LEWIS, 2009; HAYES et al., 2005).

Entretanto, para a implementação de uma estratégia de produção, é necessário dispor de processos formais para a formulação da estratégia. Em diversas pesquisas realizadas na indústria de manufatura, as evidências

\footnotetext{
${ }^{1}$ Departamento de Engenharia de Produção, Centro de Tecnologia, Universidade Federal da Paraíba - UFPB, Campus I, Bloco G, Cidade Universitária, CP 5045, CEP 58051-970, João Pessoa, PB, Brasil, e-mail: luciano@ct.ufpb.br; claudiagohr@ct.ufpb.br

2 Departamento de Engenharia e Gestão do Conhecimento, Centro Tecnológico, , Universidade Federal de Santa Catarina - UFSC, Campus Universitário, Trindade, CP 476, CEP 88040-900, Florianópolis, SC, Brasil, e-mail: grego@ deps.ufsc.br
}

Recebido em 15/2/2011 - Aceito em 24/8/2011.

Suporte financeiro: Nenhum. 
empíricas demonstraram que a formulação da estratégia de operações contribui significativamente para o desempenho competitivo e para o alinhamento estratégico do negócio (ACUR et al., 2003; PAPKESHIELDS; MALHOTRA; GROVER, 2002). Assim como na manufatura, em contextos de serviços também já foi constatado em pesquisas empíricas que a estratégia de operações causa um impacto positivo no desempenho do negócio (GOLDSTEIN; WARD, 2004; SMITH; REECE, 1999). Os resultados dessas pesquisas sinalizam a importância da adoção de procedimentos para a formulação da estratégia de operações, tanto para a manufatura quanto para os serviços.

Tradicionalmente, os procedimentos de formulação da estratégia de operações partem da definição dos requisitos de mercado (objetivos externos) e seguem com a tradução desses requisitos para os objetivos de desempenho das operações (objetivos internos) e seus desdobramentos para as principais áreas de decisão da produção (LIMA; COSTA; FARIA, 2009; MILLS et al., 2002b; HILL, 1994; GARVIN, 1993). Seguindo essa lógica, o processo tradicional de formulação da estratégia de produção parte da visão orientada pelo mercado, na qual a estratégia é guiada de "fora para dentro".

Embora a visão orientada pelo mercado seja fundamental para a formulação de uma estratégia de produção alinhada com a estratégia competitiva, também é necessário levar em consideração o papel das operações na formação de competências que muitas vezes podem se tornar essenciais para a organização. A função da estratégia de operações como desenvolvedora de competências tem sido frequentemente abordada nos trabalhos que seguem a corrente da visão baseada em recursos, uma das mais promissoras linhas de pesquisa na área (LEWIS et al., 2010; WU; MELNYK; FLYNN, 2010; PENG; SCHROEDER; SHAH, 2008).

Para incorporar a visão baseada em recursos na estratégia de produção, é importante que as empresas utilizem instrumentos adequados para identificar e avaliar suas competências e recursos estratégicos, de modo que a formulação da estratégia de operações possa ter uma abordagem mais equilibrada e direcionada para a construção de competências de longo prazo responsáveis por sustentar a vantagem competitiva da organização. Embora a importância das competências de produção seja reconhecida, grande parte dos diferentes modelos de formulação da estratégia de operações apresentados na literatura ainda são deficientes ao abordar a identificação e a análise de recursos e competências. Em geral, os modelos mais tradicionais e populares, como aqueles propostos por Hill (1994), Garvin (1993) e Slack (1993), se baseiam eminentemente na visão orientada pelo mercado, sem que haja uma análise detalhada de recursos e competências de produção. Mesmo com a evolução da visão baseada em recursos, essa constatação ainda persiste em modelos desenvolvidos mais recentemente, tais como os de Jia e Bai (2011); Lima, Costa e Faria (2009); Hurreeram (2007).

A preocupação em adotar a visão baseada em recursos na estratégia de produção também tem sido defendida para o caso específico das operações de serviços, nas quais se destacam os recursos intensivos em conhecimento (ROTH; MENOR, 2003). Nesse caso, as peculiaridades das operações de serviços justificam o desenvolvimento de teorias e técnicas específicas que, embora sejam derivadas da manufatura, demandam um esforço permanente de adaptação e adequação (SAMPSON; FROEHLE, 2006).

Contribuindo para o aumento da aplicabilidade da visão baseada em recursos em operações de serviços, este trabalho apresenta uma metodologia que se propõe a incorporar a identificação e a análise de competências no processo de formulação da estratégia de produção. Para verificar sua aplicabilidade, a metodologia proposta foi testada em uma academia de ginástica, um típico sistema de operações de serviços que apresenta recursos e processos peculiares.

Apesar de ter uma situação financeira relativamente estável, a academia estudada enfrentava os mesmos problemas da maioria das empresas ligadas ao setor de fitness, como a sazonalidade da demanda e a visão que o mercado tem da atividade física como uma atividade supérflua, o que torna as academias muito sensíveis a crises econômicas. Conscientes das turbulências em seu setor de atuação, os sócios-gerentes da empresa tinham a intenção de melhorar seus procedimentos de planejamento, de forma a guiar o desenvolvimento de competências para as operações da academia. Essa necessidade foi demonstrada pelos gerentes no contato inicial com os autores deste trabalho e os motivou a participar do projeto de pesquisa que lhes foi proposto. Considerando o escopo total do projeto, a análise de competências representava uma das etapas do processo de formulação da estratégia de operações da academia.

Após uma breve revisão de literatura, este artigo descreve o método proposto para identificação e análise de competências, bem como, a abordagem metodológica para a coleta e a análise de dados. Em seguida, a aplicação na academia de ginástica é apresentada e avaliada, precedendo as considerações finais que encerram o texto.

\section{A estratégia de operações segundo a visão baseada em recursos}

Em meados da década de 1970, a comunidade acadêmica e os profissionais de diversas organizações começaram a voltar suas atenções para o papel 
estratégico das operações e sua ligação com as estratégias corporativas e competitivas da organização. O gatilho inicial para o desenvolvimento desse assunto veio com o trabalho de Skinner (1969), que defendia que as decisões relacionadas com as operações deveriam estar alinhadas com a estratégia competitiva da organização. Desde então, a pesquisa na área se desenvolveu e o conceito de estratégia de operações tem recebido a influência de diferentes correntes de pensamento.

Ao analisar o conceito de estratégia de operações, surgem duas "escolas de pensamento" principais (SLACK; LEWIS, 2009; LOWSON, 2003): a visão orientada pelo mercado e a visão baseada em recursos. A visão orientada pelo mercado parte do princípio de que a estratégia é função dos requisitos do mercado. É como se a estratégia fosse guiada de "fora para dentro", ou seja, as características do ambiente em que a organização estivesse inserida determinariam a estratégia. A visão da estratégia de operações orientada pelo mercado é derivada dessa mesma corrente na literatura de estratégia empresarial, na qual o trabalho de Porter (1991) pode ser considerado como um dos maiores influenciadores. Porter (1996, p. 61) demonstra claramente a sua visão do conceito de estratégia quando afirma que "eficácia operacional não é estratégia". Essa afirmação encontra a oposição de Hayes e Upton (1998), defensores da visão baseada em recursos (do termo em inglês resource-based view - RBV). Para esses autores, quando a eficácia operacional é baseada nas capacitações que estão embutidas nas pessoas e nos processos operacionais de uma empresa, ela não somente sustenta a posição competitiva da organização como também passa a ser uma característica difícil para os concorrentes imitarem.

A estratégia de operações na visão baseada em recursos é guiada de "dentro para fora", tendo como objetivo principal o desenvolvimento de competências que garantem uma vantagem competitiva sustentável (SLACK; LEWIS, 2009). Na visão baseada em recursos, ao invés da estratégia de operações ser guiada pelas regras ditadas pelo mercado, o foco está em desenvolver e explorar os recursos operacionais singulares de uma empresa a fim de mudar as regras da competição (GAGNON, 1999). A visão baseada em recursos ganhou um grande destaque na literatura de estratégia empresarial com a disseminação do conceito de competências essenciais (do termo em inglês core competencies), popularizado por Prahalad e Hamel (1990). Isso influenciou fortemente a área de estratégia de operações, na qual a "visão baseada em recursos" desponta atualmente como uma de suas principais tendências (BOYER; SWINK; ROSENZWEIG, 2005; VOSS, 2005).

Porém, como a visão baseada em recursos poderia ser utilizada de maneira prática pelas organizações?
Em busca de uma resposta a essa questão, Grant (1991) defendeu que fosse adotada uma abordagem baseada em recursos (RBV) para a formulação da estratégia empresarial e sugeriu um modelo de análise estratégica fundamentado nesse princípio. De fato, a antiga preocupação com a aplicação prática da RBV continua sendo uma temática atual e pode ser observada em trabalhos recentes na área de estratégia empresarial, como os de Arend e Lévesque (2010); Kunc e Morecroft (2010).

Quando se trata do nível funcional da estratégia, pode-se afirmar que a visão baseada em recursos também poderia ser incorporada ao processo de formulação da estratégia de produção, que assumiria definitivamente o seu papel no desenvolvimento de competências operacionais. É importante ressaltar que utilizar os princípios da RBV não significa abandonar a visão orientada pelo mercado, mas sim integrar as duas abordagens em um processo de formulação mais equilibrado.

Na literatura de estratégia de operações é possível encontrar alguns estudos que tiveram o objetivo de identificação e análise de competências. Lewis (2003), por exemplo, realizou uma pesquisa para a análise de competências em três empresas do setor aeroespacial, na qual utilizou entrevistas semiestruturadas como a principal fonte de dados. De modo semelhante, Wong e Karia (2010); Escrig-Tena e Bou-Llusar (2005); Pandža et al. (2003); Coates e McDermott (2002) também conduziram pesquisas relevantes para identificar e analisar competências e recursos estratégicos no âmbito das operações. No entanto, embora essas pesquisas tenham sido originais do ponto de vista de sua contribuição científica, nenhuma delas contribuiu com uma metodologia prática que pudesse ser utilizada pelas organizações em seus procedimentos de formulação da estratégia de produção. Na verdade, esses trabalhos analisaram recursos e competências para gerar conhecimentos úteis para a pesquisa acadêmica, sem um compromisso com a aplicação direta desses conhecimentos na rotina das empresas. Para isso, usaram procedimentos metodológicos de caráter descritivo e explicativo, tais como estudos de caso (COATES; McDERMOTT, 2002; LEWIS, 2003; PANDŽA et al., 2003), análise de conteúdo em documentos publicados (WONG; KARIA, 2010) e survey (ESCRIG-TENA; BOU-LLUSAR, 2005), mais preocupados em "descrever" e "explicar" recursos e competências do que em "prescrever" e "orientar" a identificação e a análise deles nas empresas.

Embora a pesquisa explanatória seja fundamental para a acumulação de conhecimento teórico, a contribuição científica focada na aplicação do conhecimento é característica de uma abordagem de pesquisa distinta, denominada por Holmström, Ketokivi e Hameri (2009); Van Aken (2004) de abordagem das ciências do design. A pesquisa nas 
ciências do design tem o objetivo de desenvolver conhecimento válido e confiável para ser utilizado na solução de problemas do mundo real. No processo de identificação e análise de recursos e competências, os resultados esperados desse tipo de pesquisa são ferramentas de gestão orientadas para a resolução de problemas empresariais.

Com o intuito de desenvolver novas ferramentas de gestão, Nieweglowski, Lima e Costa (2010); Yang et al. (2006); Mills, Platts e Bourne (2003) propuseram metodologias práticas que foram além das pesquisas usuais sobre a aplicação da RBV no processo de formulação estratégica. No trabalho de Nieweglowski, Lima e Costa (2010), os autores incorporaram a análise de competências ao método tradicional de avaliação de projetos de investimento. Já Yang et al. (2006) estabeleceram um modelo para identificar competências essenciais operacionalizado por meio de uma aplicação computacional, porém com o foco principal em competências humanas. Mills, Platts e Bourne (2003), por sua vez, desenvolveram uma metodologia de análise de recursos e competências que demonstrou sua aplicabilidade e integração com os procedimentos formais de formulação da estratégia de produção, fator diretamente relacionado com o propósito desta pesquisa. Um dos diferenciais da metodologia desses autores é que ela considera as competências como variáveis e não como atributos, o que justifica a inclusão de um procedimento de avaliação do grau de importância de cada recurso que compõe uma competência.

Um procedimento de identificação e análise de competências normalmente segue o referencial teórico de cada autor diante do tema. Como ainda existem muitas definições divergentes sobre o assunto, cabe aqui um detalhamento do significado do conceito de competências utilizado neste artigo. Em consequência da diversidade conceitual, o termo "competências" aparece na literatura da visão baseada em recursos (RBV) com vários significados, muitas vezes podendo até ser intercambiável com o termo "recursos".

Para este trabalho, adota-se a ideia defendida por Lewis (2003) de que as competências são formadas a partir de uma combinação de recursos e processos. Nesse caso, o termo "processos" tem um significado análogo ao de "rotinas", elemento que tem sido apontado como a fonte para a formação de competências (PENG; SCHROEDER; SHAH, 2008). Além disso, essa noção é complementada pela contribuição de Mills et al. (2002a), que afirmam que essa combinação deve estar coordenada entre si, ou seja, não basta ter os recursos e os processos adequados, mas o modo que eles interagem é o que vai constituir uma competência. Aqui o conceito de coordenação tem uma relação direta com o conceito de configuração de recursos e competências apresentado por Gruber et al. (2010).
De acordo com a definição adotada neste trabalho, os recursos são formadores (e não sinônimos) das competências. Por esse motivo, para compreender melhor as competências que são identificadas em uma organização, é necessário reconhecer os recursos que a compõem. Para facilitar a identificação dos recursos envolvidos em uma competência, a literatura sugere a categorização dos recursos, de forma que o procedimento de análise seja guiado por uma espécie de check-list feito por categoria de recursos. De acordo com Mills et al. (2002a), entender as categorias a que os recursos pertencem é importante por dois motivos:

- Para que posteriormente a descrição dos recursos seja mais compreensível para aquelas pessoas que não estiveram envolvidas no processo de identificação;

- Para garantir que nenhuma categoria de recursos deixe de ser levada em consideração na análise.

Uma maneira mais abrangente para categorizar os recursos é dividindo-os em recursos tangíveis e recursos intangíveis. Essa divisão é amplamente reconhecida na literatura de estratégia empresarial, desde os clássicos trabalhos que fundamentam a visão baseada em recursos (RBV), tais como os de Penrose (1968) e de Wernerfelt (1984), até os trabalhos mais recentes na área, tais como o de Gruber et al. (2010). Esses dois tipos de recursos são definidos do seguinte modo:

- Recursos tangíveis: são aqueles recursos mais facilmente observáveis que geralmente incluem recursos físicos e humanos;

- Recursos intangíveis: são mais difíceis de identificar e quantificar e normalmente incluem recursos relacionados ao conhecimento organizacional.

Entretanto, o que caracteriza a importância de cada recurso em relação à sua contribuição para a vantagem competitiva de uma organização? Barney e Hesterly (2007) consideram que um recurso é estratégico quando ele consegue atender a quatro requisitos básicos (constituindo o que os autores denominaram de "modelo VRIO"): valor, raridade, inimitabilidade e organização, sendo este último requisito relacionado ao esforço da empresa para coordenar políticas e processos para tirar proveito desse recurso. Devido à sua relevância e praticidade, o modelo VRIO tem servido de framework para diversas pesquisas na área, como se pode observar, por exemplo, na pesquisa de Arend e Lévesque (2010).

Com uma abordagem similar à do modelo VRIO, Mills et al. (2002a) estabelecem três critérios de avaliação análogos: valor, sustentabilidade e versatilidade. Embasados na literatura, esses requisitos são coerentes com os critérios definidos anteriormente por autores tradicionais da área de 
estratégia empresarial, tais como Peteraf (1993); Prahalad e Hamel (1990).

Um ponto a ser destacado no processo de identificação e análise é que as competências são histórico-dependentes. De acordo com Barney (1991), a trajetória da organização, ilustrada pelos eventos históricos que ocorrem ao longo do tempo, exerce um papel fundamental para o desenvolvimento de competências. As circunstâncias particulares sob as quais as competências foram formadas tornam essas competências únicas e, consequentemente, difíceis de imitar. Isso demonstra a forte relação que as competências têm com o processo de formação da estratégia, embora não deixem de constituir elementos do conteúdo da estratégia.

Entender o processo de formação da estratégia ajuda a identificar "quais" competências foram desenvolvidas e também "como" elas foram desenvolvidas. Esse entendimento é realmente fundamental para a formulação de uma estratégia de operações que seja capaz de aproveitar e manter competências existentes e também guiar o desenvolvimento de novas competências.

\section{Modelo proposto}

Para a identificação e a análise de competências e recursos estratégicos das operações, foi proposto um modelo de referência, elaborado a partir de uma revisão detalhada da literatura e refinado por meio de sua aplicação em um contexto real.

As fontes de informação para a pesquisa bibliográfica foram, em sua grande maioria, artigos científicos (conceituais e empíricos) provenientes dos principais periódicos internacionais das áreas de estratégia, gestão de operações e gestão de serviços. A coleta de referências ocorreu por meio do acesso às bases de dados on-line que agregam a maioria dos periódicos de renome na área. Essas bases de dados estão disponíveis no Portal de Periódicos da CAPES (www.periodicos.capes.gov.br) e no Portal EBSCO (www.ebsco.com), que possuem acesso restrito para universidades conveniadas. A busca do material bibliográfico utilizou várias palavraschaves relacionadas com o tema da pesquisa, tais como: resource-based view, operations strategy, manufacturing strategy, service operations, etc.
Todas essas informações conferiram um alto grau de confiabilidade à pesquisa bibliográfica, garantindo que a revisão de literatura realmente correspondesse ao "estado da arte" nos assuntos pesquisados.

A pesquisa bibliográfica forneceu a base conceitual para a construção de um método de identificação e análise de recursos e competências, que representava uma parte essencial de um modelo mais abrangente que visava à formulação da estratégia de operações de serviços. Inicialmente, o método foi desenvolvido somente com base na literatura disponível. A partir da versão inicial, o modelo foi aplicado em uma academia de ginástica por meio da abordagem da pesquisa-ação, conforme será explicado na próxima seção. A aplicação foi essencial para o refinamento do método, permitindo que se fizessem ajustes na versão inicial à medida que a empresa fornecia feedbacks provenientes de situações práticas.

A versão final do modelo foi composta por três etapas básicas, tal como se observa na Figura 1.

A primeira etapa do modelo proposto adota a premissa de que as competências são históricodependentes e, por isso, se propõe a descrever a trajetória estratégica da organização. Para mapear a estratégia de operações foi feita uma adaptação da ferramenta de strategy charting proposta por Mills et al. (1998), denominada aqui como "mapa de eventos estratégicos" (Figura 2). Embora tenha um objetivo semelhante ao da ferramenta de Mills et al. (1998), o mapa de eventos estratégicos tem um procedimento de aplicação mais simplificado, o que confere uma maior facilidade de uso e diminui, por consequência, a necessidade de treinamento prévio de seus usuários. A facilidade de uso está relacionada com a lógica intuitiva da representação gráfica do mapa de eventos estratégicos que, por sua vez, vem de encontro ao conceito de visualização da estratégia, defendido por Eppler e Platts (2009).

Outra diferença marcante em relação à ferramenta original proposta por Mills et al. (1998) é que, ao invés de trabalhar com a noção de hierarquia estratégica, o mapa de eventos estratégicos explora as relações de conteúdo-contexto-processo, de modo semelhante ao que foi utilizado por Swamidass, Darlow e Baines (2001).

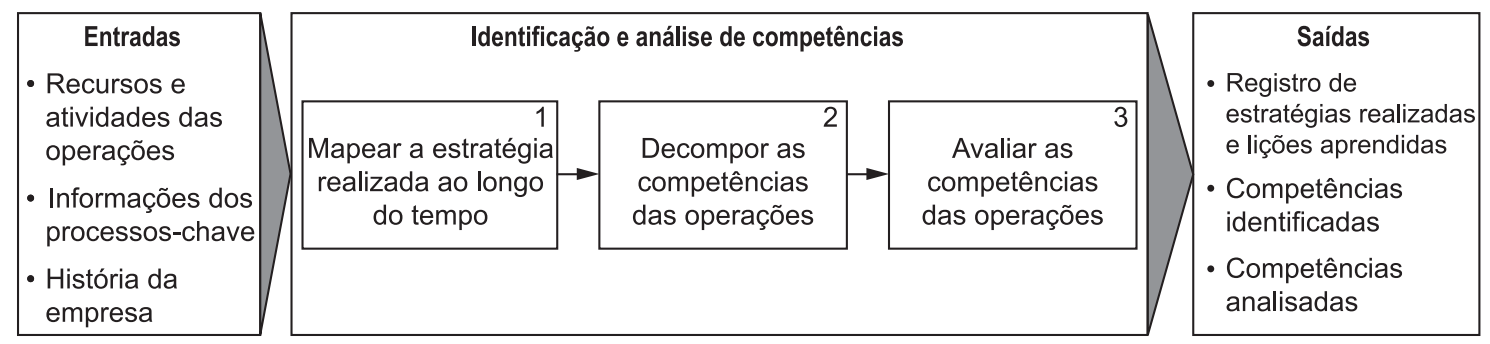

Figura 1. Modelo proposto. 


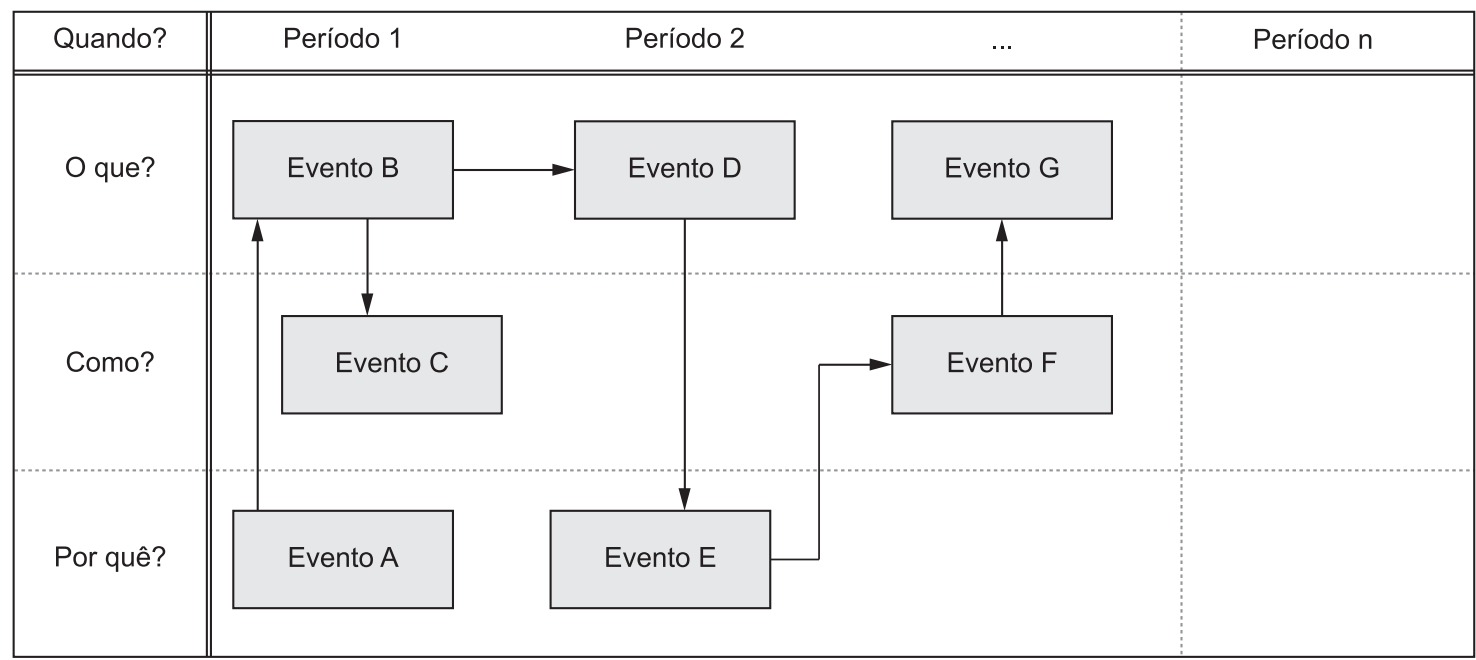

Figura 2. Representação esquemática do mapa de eventos estratégicos.

De uma forma geral, o procedimento de aplicação do mapa de eventos estratégicos envolve os seguintes passos:

- $\mathbf{1}^{\circ}$ passo: Determinar o horizonte de tempo a ser analisado;

- $\mathbf{2}^{\mathbf{0}}$ passo: Dividir o horizonte de tempo em intervalos menores (períodos) que fazem sentido para a operação que está sendo analisada.

- $3^{\mathbf{o}}$ passo: Identificar os eventos estratégicos (representados por retângulos) que ocorreram em cada intervalo de tempo, classificando-os nas seguintes dimensões:

“O que?": Descrever os eventos que caracterizaram o conteúdo das estratégias realizadas;

"Como?": Descrever os eventos que caracterizaram a maneira que as estratégias foram realizadas (processo);

"Por quê?": Descrever os eventos do contexto (externo ou interno) que influenciaram ou foram influenciados pelas estratégias realizadas.

- $\mathbf{4}^{\mathbf{0}}$ passo: Relacionar os eventos estratégicos utilizando setas que identificam as relações causa-efeito.

O levantamento de eventos passados deve ser feito em discussões de grupo envolvendo a equipe de análise estratégica e as demais pessoas que possam dar contribuições relevantes para despertar a memória das estratégias realizadas pela organização. As conclusões do mapa de eventos estratégicos devem ser registradas por escrito em três categorias: breve descrição da história, lições aprendidas e competências desenvolvidas. A descrição textual da trajetória estratégica da organização estimula os gerentes de operações a refletir sobre os eventos ilustrados no mapa. Essa reflexão possibilita o registro de lições aprendidas, que representa uma forma de incorporar a aprendizagem na estratégia de operações e direciona o desenvolvimento de competências futuras com base no conhecimento das estratégias passadas.

Ao analisar a história da empresa, é possível identificar as competências que têm sido desenvolvidas ao longo do tempo e que estão relacionadas com os eventos estratégicos que foram descritos, pois a formação de competências depende da trajetória da organização. No entanto, é provável que o mapa de eventos estratégicos não seja suficiente para identificar todas as competências das operações. Por isso, é recomendável que a identificação de competências pelo mapa de eventos estratégicos seja feita em conjunto com um brainstorming. Esse brainstorming permite identificar tanto as competências que já estão sinalizadas no mapa de eventos estratégicos quanto aquelas que foram omitidas na descrição da história da empresa.

Conforme foi abordado na seção anterior, este artigo adota a seguinte definição de competência de produção: uma combinação coordenada de recursos e processos das operações, que é desenvolvida ao longo do tempo e que garante uma vantagem competitiva para a organização. Portanto, após a identificação das competências na primeira etapa, a segunda etapa do modelo segue com a decomposição dessas competências a fim de identificar a combinação de recursos e processos que as formam.

A decomposição de recursos passa por sua categorização. Como mostra o Quadro 1, as categorias de recursos adotadas para este trabalho foram baseadas nas propostas de Mills et al. (2002a); Slack e Lewis (2009); Armistead e Clark (1993). Enquanto as duas primeiras referências definem categorias de recursos de uma forma genérica (tanto para manufatura quanto para serviços), a terceira referência procura definir categorias de recursos específicos das operações de serviços, que representam o foco deste trabalho. 
Observando a lista de categorias que foi sugerida no Quadro 1, é importante destacar que um recurso pode pertencer a mais de uma categoria. Por exemplo, um funcionário que tem um conhecimento especializado sobre um determinado processo é um recurso que certamente seria enquadrado em pelo menos duas categorias: "pessoal" e "experiência".

O formulário utilizado para auxiliar nesta atividade é demonstrado no Quadro 2. Esse formulário traz a nomenclatura de "recursos-chave" e "processoschave", com a finalidade de destacar somente os processos e os recursos que são formadores da competência identificada, e não todos os recursos envolvidos. Dessa maneira, os recursos e os processos que realmente são formadores de uma competência são considerados "chave" para essa competência. Se essa competência for essencial para as operações, eles serão considerados recursos-chave e processos-chave das operações.

Enquanto os recursos são classificados no formulário assinalando um " $\mathrm{X}$ " nas categorias a que eles pertencem, os processos-chave são detalhados de acordo com a natureza de suas atividades principais. No caso das operações de serviços, dois tipos de atividades são considerados: atividades de linha de frente (aquelas em que o cliente participa) e atividades de retaguarda (aquelas em que o cliente não participa).

Além de serem decompostas, as competências que forem identificadas devem ser avaliadas em relação ao seu potencial de contribuição para a estratégia de operações da empresa. Desse modo, pode-se considerar que diferentes competências terão diferentes graus de importância. Quanto mais importante for considerada uma competência, maior será a sua vantagem potencial e, consequentemente, a sua contribuição para a estratégia de operações.

A terceira etapa do modelo proposto utiliza os critérios de avaliação definidos por Mills et al. (2002a): valor, sustentabilidade e versatilidade. Embora esses critérios tenham sido definidos inicialmente para a avaliação de recursos estratégicos, eles foram utilizados nesse modelo com o objetivo de avaliação de competências, considerando que os fatores que

Quadro 1. Categoria de recursos das operações de serviços.

\begin{tabular}{|c|c|c|}
\hline \multicolumn{2}{|c|}{ Categorias de recursos } & Descrição \\
\hline \multirow[t]{4}{*}{ Tangíveis } & Instalações & $\begin{array}{l}\text { Estrutura física das operações de serviços. Inclui diversos elementos, tais como } \\
\text { máquinas, equipamentos, construções, decoração interna, localização, etc. }\end{array}$ \\
\hline & Pessoal & $\begin{array}{c}\text { Recursos humanos responsáveis por executar, manter e gerenciar as } \\
\text { operações de serviços. Incluem funcionários de linha de frente e } \\
\text { de retaguarda e gerentes em todos os níveis. }\end{array}$ \\
\hline & Clientes & $\begin{array}{c}\text { Clientes externos que são os destinatários do serviço. Em serviços, o cliente pode ser } \\
\text { considerado como um recurso, pois é parte integrante do sistema de operações. }\end{array}$ \\
\hline & Materiais & $\begin{array}{l}\text { Bens facilitadores consumidos no processo ou oferecidos } \\
\text { como parte do pacote. Incluem materiais que são transformados } \\
\text { pelo processo, advindos do cliente ou de fornecedores externos. }\end{array}$ \\
\hline \multirow[t]{4}{*}{ Intangíveis } & Informações & $\begin{array}{l}\text { Recursos informacionais que podem vir dos clientes e de outras fontes } \\
\text { do ambiente externo ou interno (ex.: banco de dados de clientes, } \\
\text { informações confidenciais do mercado, etc.). }\end{array}$ \\
\hline & Sistemas & $\begin{array}{l}\text { Rotinas e procedimentos que podem ser documentados ou não, } \\
\text { e que dependem de conhecimento, habilidades e } \\
\text { informações para funcionar (ex.: software, certificações ISO, etc.). }\end{array}$ \\
\hline & Experiência & $\begin{array}{l}\text { Conhecimento tácito não documentado na forma de sistemas que foi desenvolvido ao } \\
\text { longo do tempo. Inclui também a cultura e os valores da organização. }\end{array}$ \\
\hline & Relacionamento & $\begin{array}{c}\text { Relação com todos os grupos de interesse (stakeholders) e reputação } \\
\text { da empresa no mercado. Inclui parcerias e alianças estratégicas, } \\
\text { relações com o governo, redes informais, etc. }\end{array}$ \\
\hline
\end{tabular}

Quadro 2. Formulário para decomposição de competências.

\begin{tabular}{|c|c|c|c|c|c|c|c|c|}
\hline Competência & & & & & & & & \\
\hline Recursos-chave & & Tan & íveis & & & & tangíveis & \\
\hline & Instalações & Pessoal & Clientes & Materiais & Informações & Sistemas & Experiência & Relacionamento \\
\hline & & & & & & & & \\
\hline & & & & & & & & \\
\hline Processos-chave & Ativi & dades de & linha de $\mathrm{fr}_{1}$ & ente & & Atividad & es de retaguar & \\
\hline & & & & & & & & \\
\hline & & & & & & & & \\
\hline
\end{tabular}


tornam uma competência importante são os mesmos que tornam um recurso importante. Segue abaixo o significado de cada um desses critérios:

- Valor: significa que a competência contribui consideravelmente para o valor percebido pelo cliente, gerando um incremento na lucratividade como consequência. Uma competência valiosa é aquela que confere uma vantagem competitiva para a empresa, possibilitando aproveitar oportunidades de mercado e afastar ameaças iminentes. Recursos raros ou escassos tendem a ter um valor maior, portanto, as competências que são formadas por esse tipo de recurso geralmente são consideradas valiosas;

- Sustentabilidade: significa que o valor da competência pode ser mantido ao longo do tempo, sendo pouco depreciável. Para uma competência ser sustentável, ela deve ser de difícil imitação, seja pelo fato de os concorrentes não reconhecerem facilmente a competência ou por ela ter sido desenvolvida em circunstâncias específicas da história da organização. A sustentabilidade de uma competência também é aumentada pela sua dificuldade de substituição por outras competências, sendo que a situação ideal seria quando nenhuma outra competência conseguisse garantir as mesmas vantagens competitivas que ela garante;
- Versatilidade: significa que a competência pode ser transferida para outros serviços e mercados, ou mesmo, para outros negócios da organização. Essa característica parte da premissa de que o conhecimento contido em uma competência pode ser utilizado de outras maneiras que vão além de sua aplicação atual e que podem ser igualmente vantajosas para a empresa. Em geral, uma competência versátil não depende muito de recursos e processos complementares, não está vinculada a nenhuma região geográfica e também não necessita de muito tempo para ser transferida. Outro fator que contribui para aumentar a versatilidade de uma competência é o grau de conhecimento explícito que se tem sobre ela, seja documentado ou codificado de outras formas. Isso ocorre devido ao fato de o conhecimento tácito ser mais difícil de ser reproduzido do que o conhecimento explícito (NONAKA, 1994).

Para avaliar o grau de importância em cada um dos critérios, o modelo proposto adotou os formulários sugeridos por Mills et al. (2002a), com apenas algumas adaptações no formulário de avaliação da versatilidade. Os formulários para a realização da terceira etapa são apresentados nos Quadros 3, 4 e 5.

Apesar de os formulários de avaliação de competências assumirem a forma de questionários,

Quadro 3. Formulário para avaliação do valor da competência.

\begin{tabular}{|c|c|c|c|c|c|c|c|}
\hline Competência & & & & & & & \\
\hline & Avaliação c & do valor da & competênci & & & Desconhecido & Não \\
\hline $\begin{array}{l}\text { Qual é o seu efeito } \\
\text { sobre a lucratividade }\end{array}$ & $\begin{array}{c}\text { Altamente } \\
\text { negativo }\end{array}$ & $\begin{array}{l}\text { Impacto } \\
\text { negativo }\end{array}$ & $\begin{array}{l}\text { Impacto } \\
\text { nulo }\end{array}$ & $\begin{array}{l}\text { Impacto } \\
\text { positivo }\end{array}$ & $\begin{array}{l}\text { Altamente } \\
\text { positivo }\end{array}$ & & \\
\hline da organização? & & & & & & & \\
\hline $\begin{array}{l}\text { Qual é o seu efeito sobre a } \\
\text { habilidade da organização } \\
\text { para evitar as ameaças? }\end{array}$ & & & & & & & \\
\hline $\begin{array}{l}\text { Qual é o seu efeito sobre a } \\
\text { habilidade para aproveitar } \\
\text { as oportunidades? }\end{array}$ & & & & & & & \\
\hline Quantos concorrentes & Todos & A maioria & Metade & Alguns & Nenhum & & \\
\hline competência? & & & & & & & \\
\hline $\begin{array}{l}\text { Comparando com a } \\
\text { concorrência, qual é o } \\
\text { nível de desempenho }\end{array}$ & $\begin{array}{l}\text { Muito } \\
\text { abaixo da } \\
\text { média }\end{array}$ & $\begin{array}{c}\text { Abaixo da } \\
\text { média do } \\
\text { setor }\end{array}$ & $\begin{array}{c}\text { Na média } \\
\text { do setor }\end{array}$ & $\begin{array}{c}\text { No nível dos } \\
\text { melhores }\end{array}$ & $\begin{array}{c}\text { Liderança } \\
\text { inquestionável }\end{array}$ & & \\
\hline desta competência? & & & & & & & \\
\hline $\begin{array}{c}\text { Qual declaração melhor } \\
\text { ilustra o valor desta } \\
\text { competência? }\end{array}$ & & & & & & & \\
\hline Resumo do & Negativo & Baixo & & Médio & Alto & Desco & onhecido \\
\hline valor & & & & & & & \\
\hline
\end{tabular}

Fonte: Mills et al. (2002a). 
Quadro 4. Formulário para avaliação da sustentabilidade da competência.

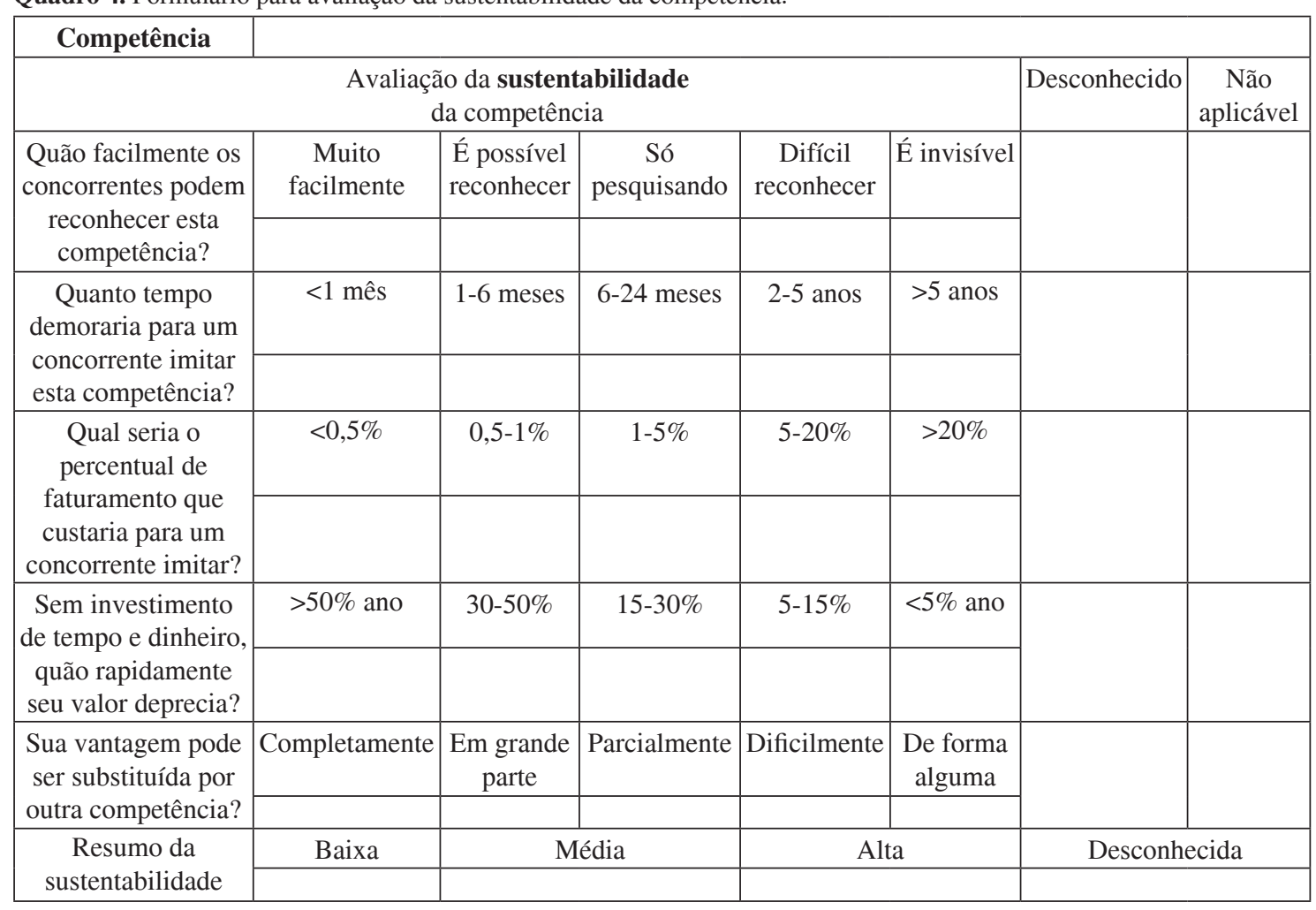

Fonte: Mills et al. (2002a).

o preenchimento deles se dá por consenso entre os participantes do processo de análise, e não pela média das respostas. Mesmo naquelas questões em que aparece uma escala numérica para avaliação da competência, a análise é predominantemente qualitativa, pois as respostas dependem de um alto grau de julgamento pessoal dos envolvidos no processo.

Nem sempre uma competência terá o mesmo grau de importância em todos os critérios. Em alguns casos, ter uma competência bem avaliada em apenas um critério já pode garantir uma vantagem significativa. Em outros casos, pode inclusive haver um conflito entre a sustentabilidade e a versatilidade, pois o conhecimento tácito tende a ser mais sustentável, porém mais difícil de transferir. O fato é que o estrategista deve conhecer o grau de importância de uma competência em cada critério para que ele possa formular uma estratégia de operações que esteja orientada para o desenvolvimento de competências valiosas, sustentáveis e versáteis.

\section{Procedimentos metodológicos para a aplicação}

Do ponto de vista da metodologia científica, pode-se afirmar que a aplicação do modelo foi realizada dentro dos moldes da pesquisa-ação, um método que tem sido aconselhado em pesquisas na área de gestão de operações (COUGHLAN; COGHLAN, 2002). Na pesquisa-ação o pesquisador intervém na realidade organizacional e envolve o objeto pesquisado para o alcance dos objetivos da pesquisa (EDEN; HUXHAM, 1996). Neste trabalho, o envolvimento entre os pesquisadores e o objeto pesquisado ocorreu por meio da aplicação do método proposto, que foi testado in loco nas operações de uma academia de ginástica.

A equipe de intervenção da pesquisa-ação foi composta por quatro pessoas: os dois sócios-gerentes da academia, um pesquisador-líder (facilitador externo) e um bolsista de iniciação científica do curso de graduação em Engenharia de Produção, que auxiliou na coleta de dados internos e externos. Durante o processo de pesquisa, a equipe se reunia periodicamente para analisar os dados que haviam sido coletados e discutir as possíveis alternativas estratégicas para a empresa, já que a análise de competências era uma das etapas do processo de formulação da estratégia de operações da academia.

A unidade de análise na pesquisa de campo foi definida de acordo com a proposição de Acur e Bititci (2003), na qual a unidade de análise na perspectiva da estratégia de operações engloba os processos ligados à produção, equivalendo em serviços, aos processos operacionais com atividades de linha de frente e de retaguarda. Durante a pesquisa, o próprio método de identificação e análise de competências funcionou como 
Quadro 5. Formulário para avaliação da versatilidade da competência.

\begin{tabular}{|c|c|c|c|c|c|c|c|}
\hline \multicolumn{8}{|l|}{ Competência } \\
\hline \multicolumn{6}{|c|}{$\begin{array}{c}\text { Avaliação da versatilidade } \\
\text { da competência }\end{array}$} & \multirow[t]{3}{*}{\begin{tabular}{|l|} 
Desconhecido \\
\end{tabular}} & \multirow[t]{3}{*}{\begin{tabular}{|c|} 
Não \\
aplicável
\end{tabular}} \\
\hline \multirow{2}{*}{$\begin{array}{c}\text { A competência } \\
\text { pode ser transferida } \\
\text { para outros serviços } \\
\text { e mercados da } \\
\text { empresa? }\end{array}$} & Impossível & \begin{tabular}{|c|} 
Com \\
dificuldade
\end{tabular} & \begin{tabular}{|c|} 
Com algum \\
esforço
\end{tabular} & Facilmente & $\begin{array}{l}\text { Muito } \\
\text { facilmente }\end{array}$ & & \\
\hline & & & & & & & \\
\hline \multirow{2}{*}{\begin{tabular}{|c|} 
Esta competência \\
depende de recursos \\
e/ou processos \\
complementares \\
para ser transferida?
\end{tabular}} & Completamente & $\begin{array}{l}\text { Depende } \\
\text { bastante }\end{array}$ & Parcialmente & $\begin{array}{c}\text { Depende } \\
\text { pouco }\end{array}$ & Independente & & \\
\hline & & & & & & & \\
\hline \multirow{2}{*}{$\begin{array}{l}\text { Esta competência } \\
\text { está vinculada } \\
\text { a alguma região } \\
\text { geográfica? }\end{array}$} & Vínculo total & $\begin{array}{l}\text { Vínculo } \\
\text { forte }\end{array}$ & $\begin{array}{l}\text { Vínculo } \\
\text { parcial }\end{array}$ & $\begin{array}{l}\text { Vínculo } \\
\text { fraco }\end{array}$ & $\begin{array}{l}\text { Nenhum } \\
\text { vínculo }\end{array}$ & & \\
\hline & & & & & & & \\
\hline \multirow{2}{*}{$\begin{array}{l}\text { Quanto tempo } \\
\text { demoraria para } \\
\text { reproduzir esta } \\
\text { competência em } \\
\text { outra parte da } \\
\text { organização? }\end{array}$} & $>5$ anos & $2-5$ anos & 6-24 meses & 1-6 meses & $<1$ mês & & \\
\hline & & & & & & & \\
\hline \multirow{2}{*}{$\begin{array}{l}\text { A organização tem } \\
\text { um conhecimento } \\
\text { explícito dos } \\
\text { fatores necessários } \\
\text { para reproduzir } \\
\text { esta competência? }\end{array}$} & $\begin{array}{l}\text { De forma } \\
\text { alguma }\end{array}$ & $\begin{array}{l}\text { Muito } \\
\text { pouco }\end{array}$ & Parcialmente & $\begin{array}{c}\text { Em grande } \\
\text { parte }\end{array}$ & Completamente & & \\
\hline & & & & & & & \\
\hline \multirow{2}{*}{$\begin{array}{c}\text { Resumo da } \\
\text { versatilidade }\end{array}$} & Baixa & \multirow{2}{*}{\multicolumn{2}{|c|}{ Média }} & & Alta & \multirow{2}{*}{\multicolumn{2}{|c|}{ Desconhecida }} \\
\hline & & & & & & & \\
\hline
\end{tabular}

Fonte: Adaptado de Mills et al. (2002a).

um instrumento para a obtenção de dados, abrangendo o escopo dos processos de serviços da empresa.

Os dados gerados pela aplicação do método foram analisados e documentados durante o processo de pesquisa, pois a análise de dados na pesquisa-ação ocorre em paralelo à coleta. Assim, a aplicação, o teste e o refinamento do modelo foram atividades que aconteceram simultaneamente.

O teste da aplicabilidade do modelo se baseou nos três critérios sugeridos por Platts (1993), que servem de referência para a avaliação de procedimentos de formulação da estratégia:

- Factibilidade: O modelo pode ser utilizado na prática?

- Usabilidade: O modelo é fácil de usar?

- Utilidade: O modelo traz resultados relevantes?

De acordo com Platts (1993), o teste da aplicabilidade segundo esses três critérios pode ser realizado diretamente com os usuários do modelo. $\mathrm{O}$ autor recomenda que essa verificação seja feita por meio de entrevistas pessoais ou de questionários estruturados que podem ser distribuídos aos participantes do processo de análise estratégica.
No caso específico da aplicação do modelo proposto, o grupo reduzido de participantes da pesquisa de campo (apenas quatro pessoas na equipe de aplicação) não justificava a elaboração de questionários estruturados. Assim, optou-se por coletar as evidências quanto à aplicabilidade de uma maneira menos formal, por meio de entrevistas não estruturadas com os gerentes da empresa pesquisada, realizadas ao longo do processo interativo de pesquisa. Além da opinião dos gerentes, os fatos que iam sendo observados e que permitiam avaliar a factibilidade, a usabilidade e a utilidade do método eram anotados sistematicamente após cada reunião de trabalho.

A aplicação da metodologia proposta é descrita na próxima seção. Nessa descrição, optou-se por não divulgar o nome da empresa e os dados que pudessem identificá-la, pelo fato de o trabalho envolver informações estratégicas.

\section{Aplicação em uma academia de ginástica}

A academia de ginástica selecionada para a aplicação da metodologia apresentava as principais 
características presentes na maioria das operações de serviços (intangibilidade, simultaneidade e participação), tendo o foco predominante nos processos de linha de frente.

Possuindo instalações modernas, a academia estava localizada nas dependências de um shopping center de uma grande cidade, o que lhe conferia o status característico das academias de shopping. Esses aspectos influenciavam no perfil de sua clientela, que era composta basicamente de pessoas das classes A e B. O volume de clientes da academia variava de 400 a 700 alunos matriculados, de acordo com a época do ano. Como em qualquer negócio desse setor, a procura por atividades físicas aumentava nos meses que antecedem o verão, sendo também influenciada pelas condições climáticas de cada ano.

$O$ pequeno porte da empresa facilitava na agilidade para a tomada de decisões. Todas as decisões estratégicas eram tomadas pelos dois proprietários, que possuíam a vantagem de conhecer de perto os problemas da linha de frente, pois eles também trabalhavam em contato direto com o cliente. Apesar disso, a academia tinha dificuldades na formalização de suas estratégias, um dos fatores que motivaram a sua participação nesta pesquisa.

A aplicação de cada uma das etapas do modelo é apresentada a seguir.

\subsection{Mapeamento da estratégia realizada}

Na aplicação da primeira etapa da metodologia proposta, foi delimitado um horizonte de tempo de dois anos, que correspondia ao tempo de existência da academia. Para isso, o horizonte de tempo analisado foi dividido em períodos semestrais, iniciando a partir da inauguração da empresa. Mesmo com poucos eventos estratégicos para analisar (em função da curta história da empresa), foi possível fazer uma análise representativa, que resultou no mapa apresentado na Figura 3.

A análise histórica da empresa evidenciou a estratégia de "tentativa e erro" que a empresa utilizava para a introdução de novos serviços. Primeiro, a aceitação do serviço era testada no mercado, de preferência sem comprometer recursos da empresa (em geral, por meio da terceirização). Depois, a empresa poderia ou não incorporar o novo serviço em seu portfólio, de acordo com a sua aceitação.

Outro fator que chamou a atenção e estava preocupando os gerentes da empresa há bastante tempo era a falta de comprometimento dos professores com a academia. Como os professores eram remunerados por hora-aula, uma prática comum no setor, era muito difícil garantir que eles tivessem uma dedicação compatível com a implementação de qualquer estratégia de longo prazo na empresa. A busca desse comprometimento levou a empresa a adotar estratégias de alterações na estrutura societária, que mais tarde foram consideradas equivocadas. Mesmo com isso, a falta de comprometimento ainda continuava sendo um tema preocupante e dificultava o desenvolvimento dos professores como recursos estratégicos.

Para complementar a análise, foi feito um brainstorming entre os participantes da equipe com

\begin{tabular}{|c|c|c|c|c|}
\hline Quando? & $2^{\circ}$ semestre do ano 1 & $1^{\circ}$ semestre do ano 2 & $2^{\circ}$ semestre do ano 2 & $1^{\circ}$ semestre do ano 3 \\
\hline \multirow{5}{*}{ O que? } & $\begin{array}{c}\text { Introdução e retirada } \\
\text { do Body Combat }\end{array}$ & $\begin{array}{l}\text { Introdução da } \\
\text { dança }\end{array}$ & \multirow{2}{*}{$\begin{array}{l}\text { Início da cobrança } \\
\text { de estacionamento }\end{array}$} & $\begin{array}{l}\text { Introdução e retirada } \\
\text { da massoterapia }\end{array}$ \\
\hline & \multirow{3}{*}{\begin{tabular}{|c|} 
Inauguração da \\
academia com os \\
serviços de \\
musculação e ginástica \\
\end{tabular}} & \multirow[t]{4}{*}{4} & & \multirow{4}{*}{\begin{tabular}{|c|}
$\begin{array}{c}\text { Introdução de } \\
\text { artes marciais }\end{array}$ \\
$\begin{array}{c}\text { Alteração contratual: } \\
\text { volta a ter } 2 \text { sócios } \\
(50 \% \text { cada })\end{array}$ \\
\end{tabular}} \\
\hline & & & \multirow{3}{*}{$\begin{array}{l}\text { Alteração contratual: } \\
\text { acréscimo de mais } 4 \\
\text { sócios com } 5 \% \text { cada }\end{array}$} & \\
\hline & & & & \\
\hline & 4 & & & \\
\hline \multirow{3}{*}{ Como? } & \multirow{2}{*}{$\begin{array}{l}\text { - Divulgação no site } \\
\text { do shopping } \\
\text { - } 2 \text { semanas com } \\
\text { musculação e } \\
\text { ginástica gratuitas }\end{array}$} & \multirow[b]{2}{*}{$\begin{array}{l}\text { Contratação de } \\
\text { professores } \\
\text { de dança }\end{array}$} & \multirow[b]{2}{*}{\begin{tabular}{|l|} 
Negociação com \\
os professores ao \\
longo do período
\end{tabular}} & $\Lambda$ \\
\hline & & & & $\begin{array}{l}\text { Negociação com } \\
\text { os professores ao } \\
\text { longo do período }\end{array}$ \\
\hline & $\begin{array}{l}\text { Estudos de } \\
\text { mercado feitos } \\
\text { anteriormente }\end{array}$ & & 4 & 4 \\
\hline \multirow{2}{*}{ Por quê? } & $\downarrow$ & \multirow[b]{2}{*}{$\begin{array}{c}\text { Atrair clientes } \\
\text { pré-adolescentes } \\
(10-14 \text { anos })\end{array}$} & \begin{tabular}{|c|} 
Necessidade de \\
estimular o \\
comprometimento \\
dos professores
\end{tabular} & $\begin{array}{c}\text { Identificação da } \\
\text { oportunidade de } \\
\text { mercado }\end{array}$ \\
\hline & $\begin{array}{l}\text { Identificação da } \\
\text { oportunidade de } \\
\text { mercado }\end{array}$ & & $\begin{array}{l}\text { Shopping passa a } \\
\text { terceirizar o serviço } \\
\text { de estacionamento }\end{array}$ & $\begin{array}{l}\text { Foi constatado que } \\
\text { os professores não } \\
\text { aumentaram o seu } \\
\text { comprometimento }\end{array}$ \\
\hline
\end{tabular}

Figura 3. Mapa de eventos estratégicos da academia. 
o objetivo de complementar a análise histórica e identificar quais eram realmente as competências das operações da academia. Apesar de contar com um número reduzido de pessoas, quando comparado com o de uma sessão de brainstorming tradicional, foi possível levantar um número razoável de competências das operações.

Dentre as competências identificadas, destacou-se a competência que recebeu o nome de "excelência na musculação". Ela foi denominada dessa forma devido à capacidade da empresa em oferecer um serviço de musculação de alto nível, comparável ao padrão das melhores academias do País. Além disso, a estratégia da empresa estava apoiada neste diferencial e suas operações contribuíam para reforçá-lo.

Devido à sua relevância para a empresa, a competência "excelência na musculação" foi escolhida para demonstrar neste artigo a aplicação das etapas posteriores do método proposto.

\subsection{Decomposição de competências}

Na decomposição da competência "excelência na musculação", apresentada no Quadro 6, não havia a intenção de enumerar o total de recursos e processos que poderiam estar envolvidos com esta competência. O foco dessa análise era destacar somente os recursos e os processos "formadores" da competência, que garantiam que ela fosse vista desse modo.

A identificação dos recursos-chave e dos processoschave sinalizou aqueles elementos que deveriam ser gerenciados com atenção para que a competência pudesse continuar gerando vantagem competitiva.
De fato, essa decomposição foi muito importante, pois motivou os gerentes da academia a pensar em estratégias que pudessem garantir o desenvolvimento e a manutenção de suas competências, por meio dos recursos e dos processos relacionados.

\subsection{Avaliação de competências}

Após a decomposição da competência "excelência na musculação", o seu grau de importância foi avaliado em relação ao valor, à sustentabilidade e à versatilidade. Essa tarefa foi feita com o auxílio dos formulários destinados para tal, que são apresentados nos Quadros 7, 8 e 9. Na avaliação dessa competência, feita por consenso do grupo, foi possível constatar que, embora ela fosse altamente valiosa, era medianamente sustentável e versátil.

A versatilidade moderada da competência "excelência na musculação" não foi um fator preocupante para a empresa, pois se tratava de uma competência inerente a um serviço específico, não havendo, a princípio, a intenção de que ela fosse transferida para outros serviços. A dimensão da versatilidade que interessava à empresa era a possibilidade da competência ser transferida para outros mercados geográficos, pois futuramente a academia poderia adotar estratégias de expansão, que envolviam a abertura de filiais em outras regiões da cidade. Considerando somente o centro urbano em que academia estava inserida, a competência "excelência na musculação" passava a ser bem avaliada nessa dimensão da versatilidade, pois nesse caso não haveria muitos vínculos geográficos que a impedissem de ser transferida.

Quadro 6. Decomposição da competência "excelência na musculação".

\begin{tabular}{|c|c|c|c|c|c|c|c|c|}
\hline \multirow{3}{*}{$\begin{array}{c}\text { Competência } \\
\text { Recursos-chave }\end{array}$} & \multicolumn{8}{|c|}{ Excelência na musculação } \\
\hline & \multicolumn{4}{|c|}{ Tangíveis } & \multicolumn{4}{|c|}{ Intangíveis } \\
\hline & Instalações & Pessoal & Clientes & Materiais & Informações & Sistemas & Experiência & Relacionamento \\
\hline $\begin{array}{l}\text { Professores } \\
\text { competentes }\end{array}$ & & $\mathrm{X}$ & & & & & $\mathrm{X}$ & $\mathrm{X}$ \\
\hline $\begin{array}{l}\text { Equipamentos } \\
\text { modernos }\end{array}$ & $\mathrm{X}$ & & & $\mathrm{X}$ & & & & \\
\hline $\begin{array}{c}\begin{array}{c}\text { Software de } \\
\text { avaliação física }\end{array} \\
\end{array}$ & & & & & $\mathrm{X}$ & $\mathrm{X}$ & & \\
\hline $\begin{array}{l}\text { Ambiente } \\
\text { agradável }\end{array}$ & $\mathrm{X}$ & $\mathrm{X}$ & $\mathrm{X}$ & & & & & $\mathrm{X}$ \\
\hline $\begin{array}{c}\text { Coordenador } \\
\text { da musculação }\end{array}$ & & $\mathrm{X}$ & & & & & $\mathrm{X}$ & $\mathrm{X}$ \\
\hline Processos-chave & \multicolumn{4}{|c|}{$\begin{array}{l}\text { Atividades de } \\
\text { linha de frente }\end{array}$} & \multicolumn{4}{|c|}{$\begin{array}{l}\text { Atividades de } \\
\text { retaguarda }\end{array}$} \\
\hline $\begin{array}{l}\text { Instrução } \\
\text { musculação }\end{array}$ & \multicolumn{4}{|c|}{ Entrevistar aluno, acompanhar programa } & \multicolumn{4}{|c|}{ Montar programa de exercícios } \\
\hline $\begin{array}{l}\text { Avaliação } \\
\text { física }\end{array}$ & \multicolumn{4}{|c|}{$\begin{array}{l}\text { Efetuar medidas, apresentar resultados } \\
\text { ao aluno }\end{array}$} & \multicolumn{4}{|c|}{ Processar dados do aluno } \\
\hline Manutenção & \multicolumn{4}{|c|}{-} & \multicolumn{4}{|c|}{ Monitorar, manter e consertar equipamentos } \\
\hline
\end{tabular}


Quadro 7. Valor da competência "excelência na musculação".

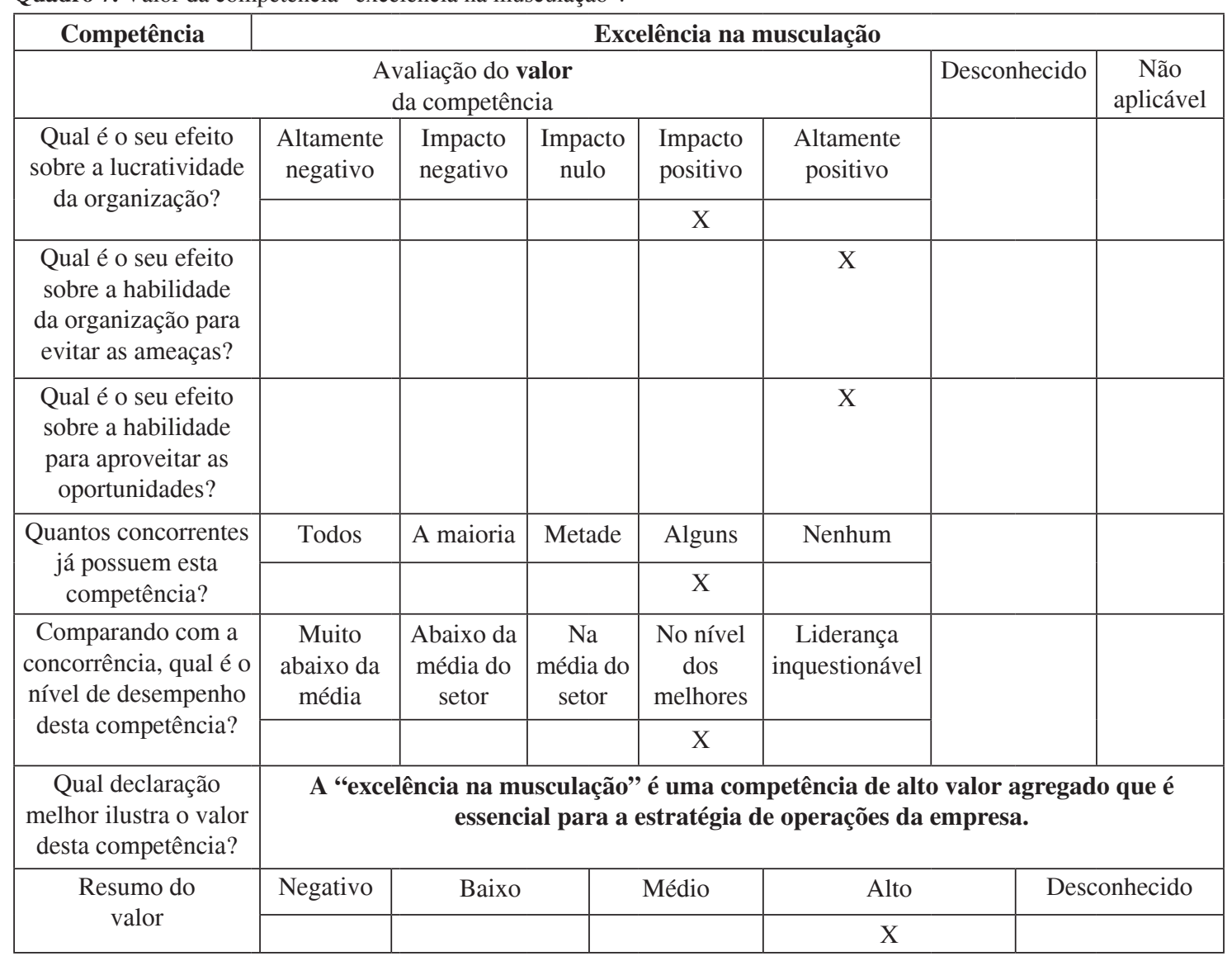

A moderada sustentabilidade da competência "excelência na musculação" pôde ser parcialmente explicada pelo fato de a empresa ser relativamente nova para que essa competência estivesse vinculada a circunstâncias específicas de sua história particular. Parte dos recursos-chave formadores dessa competência estava relacionada à estrutura física que a academia possuía (equipamentos e instalações), que poderia ser copiada por qualquer concorrente que dispusesse do capital necessário para investir em recursos equivalentes. Já os professores, também considerados recursos-chave, não tinham demonstrado um comprometimento suficiente para garantir a sustentabilidade dessa competência a longo prazo. Em resumo, embora a "excelência na musculação" fosse uma competência valiosa, nada garantia que esse valor seria mantido ao longo do tempo (sustentabilidade).

O que fazia com que a "excelência na musculação" ainda tivesse uma sustentabilidade média (e não baixa) era o grau de coordenação entre os recursos e os processos que a compunham. Mesmo que alguns de seus recursos-chave e processos-chave pudessem ser copiados, ou até mesmo substituídos, a forma que eles eram coordenados já não era tão fácil para um concorrente imitar. Isso se devia principalmente ao fato de um dos sócios ocupar a posição de coordenador da musculação, representando um recurso-chave que ajudava a garantir que a combinação de recursos e processos adequada fosse coordenada para realmente constituir uma competência essencial das operações. Entretanto, essa coordenação eficaz, resultado da experiência que já tinha sido acumulada pelo gerente antes do início do negócio, ainda não era suficiente para garantir uma alta sustentabilidade para a "excelência na musculação".

Como a estratégia de operações da academia está fortemente apoiada na competência "excelência na musculação", após a aplicação da metodologia, os gerentes da academia ficaram motivados em buscar estratégias que pudessem aumentar a sustentabilidade dessa competência.

\section{Aplicabilidade do método}

Conforme foi mencionado anteriormente, para verificar a aplicabilidade do método foram utilizados os critérios sugeridos por Platts (1993): factibilidade, usabilidade e utilidade. A seguir, é apresentada uma síntese das conclusões relacionadas aos três critérios de aplicabilidade.

A factibilidade do método proposto está relacionada à sua capacidade de ser aplicado dentro 
Quadro 8. Sustentabilidade da competência "excelência na musculação".

\begin{tabular}{|c|c|c|c|c|c|c|c|}
\hline \multirow[t]{2}{*}{ Competência } & \multicolumn{7}{|c|}{ Excelência na musculação } \\
\hline & \multicolumn{3}{|c|}{$\begin{array}{c}\text { Avaliação da sustentabilidade } \\
\text { da competência }\end{array}$} & & & Desconhecido & $\begin{array}{l}\text { Não } \\
\text { aplicável }\end{array}$ \\
\hline \multirow{2}{*}{$\begin{array}{l}\text { Quão facilmente } \\
\text { os concorrentes } \\
\text { podem reconhecer } \\
\text { esta competência? }\end{array}$} & $\begin{array}{c}\text { Muito } \\
\text { facilmente }\end{array}$ & $\begin{array}{l}\text { É possível } \\
\text { reconhecer }\end{array}$ & $\begin{array}{c}\text { Só } \\
\text { pesquisando }\end{array}$ & $\begin{array}{l}\text { Difícil } \\
\text { reconhecer }\end{array}$ & $\begin{array}{c}\text { É } \\
\text { invisível }\end{array}$ & & \\
\hline & & $\mathrm{X}$ & & & & & \\
\hline \multirow{2}{*}{$\begin{array}{l}\text { Quanto tempo } \\
\text { demoraria para } \\
\text { um concorrente } \\
\text { imitar esta } \\
\text { competência? }\end{array}$} & $<1$ mês & 1-6 meses & 6-24 meses & $2-5$ anos & $>5$ anos & & \\
\hline & & & $\mathrm{X}$ & & & & \\
\hline \multirow{2}{*}{$\begin{array}{l}\text { Qual seria o } \\
\text { percentual de } \\
\text { faturamento que } \\
\text { custaria para } \\
\text { um concorrente } \\
\text { imitar? }\end{array}$} & $<0,5 \%$ & $0,5-1 \%$ & $1-5 \%$ & $5-20 \%$ & $>20 \%$ & & \\
\hline & & & & $\mathrm{X}$ & & & \\
\hline \multirow{2}{*}{$\begin{array}{c}\text { Sem investimento } \\
\text { de tempo e } \\
\text { dinheiro, quão } \\
\text { rapidamente seu } \\
\text { valor deprecia? }\end{array}$} & $>50 \%$ ano & $30-50 \%$ & $15-30 \%$ & $5-15 \%$ & $<5 \%$ ano & & \\
\hline & & & & $X$ & & & \\
\hline \multirow{2}{*}{$\begin{array}{l}\text { Sua vantagem } \\
\text { pode ser } \\
\text { substituída } \\
\text { por outra } \\
\text { competência? }\end{array}$} & Completamente & $\begin{array}{l}\text { Em grande } \\
\text { parte }\end{array}$ & Parcialmente & Dificilmente & $\begin{array}{c}\text { De forma } \\
\text { alguma }\end{array}$ & & \\
\hline & & & & & $\mathrm{X}$ & & \\
\hline \multirow{2}{*}{$\begin{array}{c}\text { Resumo da } \\
\text { sustentabilidade }\end{array}$} & Baixa & \multicolumn{2}{|c|}{ Média } & \multicolumn{2}{|c|}{ Alta } & \multicolumn{2}{|c|}{ Desconhecida } \\
\hline & & \multicolumn{2}{|c|}{$\mathrm{X}$} & & & & \\
\hline
\end{tabular}

das condições reais das operações. Na aplicação do método, foi possível constatar que existia uma grande aderência do modelo às peculiaridades das operações da academia, fato que foi confirmado pelo depoimento dos gerentes da empresa. As informações que foram necessárias para a aplicação eram condizentes com a realidade da empresa, sendo que as etapas do método poderiam ser executadas com o rigor acadêmico que era requerido, mas ainda sem perder a sua característica essencial de praticidade.

Tipicamente, o sistema de operações de uma academia de ginástica é mais concentrado na linha de frente e apresenta as principais características dos serviços em seus processos. Trata-se de um serviço de alto contato, predominantemente intangível e dirigido a pessoas, em que prevalece o fluxo de clientes em seus processos operacionais, processos nos quais o cliente participa como coprodutor. Essas características, presentes de modo contundente na academia pesquisada, representam as principais diferenças entre as operações de serviços e as operações de manufatura. Por causa dessas características, as técnicas tradicionais da manufatura nem sempre são aplicáveis em serviços "puros", ou seja, aqueles que se posicionam no lado mais intangível do continuum entre bens e serviços. Portanto, mesmo considerando o potencial limitado para a generalização que decorre de uma única aplicação, é possível afirmar que o método proposto também pode ser factível em outras operações de serviços assim como foi para as operações da academia, já que esta permitiu testar o modelo diante das especificidades mais marcantes dos serviços.

A factibilidade do método também foi influenciada pelo alto grau de envolvimento dos gerentes, sem o qual não seria possível obter informações confiáveis para o estudo, em especial na construção do mapa de eventos estratégicos e na identificação da competência essencial da organização. Por se tratar de uma empresa nova e de pequeno porte, com gerentes abertos à mudança e que trabalhavam em contato direto com o cliente, havia uma propensão natural para um maior envolvimento gerencial. Com essa observação, pôde-se concluir que o envolvimento e a participação dos gerentes são condições fundamentais para que o método seja factível. 
Quadro 9. Versatilidade da competência "excelência na musculação".

\begin{tabular}{|c|c|c|c|c|c|c|c|}
\hline Competência & \multicolumn{7}{|c|}{ Excelência na musculação } \\
\hline \multicolumn{6}{|c|}{$\begin{array}{c}\text { Avaliação da versatilidade } \\
\text { da competência }\end{array}$} & Desconhecido & $\begin{array}{c}\text { Não } \\
\text { aplicável }\end{array}$ \\
\hline \multirow{2}{*}{$\begin{array}{c}\text { A competência } \\
\text { pode ser transferida } \\
\text { para outros serviços } \\
\text { e mercados da } \\
\text { empresa? }\end{array}$} & Impossível & $\begin{array}{c}\text { Com } \\
\text { dificuldade }\end{array}$ & $\begin{array}{c}\text { Com algum } \\
\text { esforço }\end{array}$ & Facilmente & $\begin{array}{l}\text { Muito } \\
\text { facilmente }\end{array}$ & & \\
\hline & & & $\mathrm{X}$ & & & & \\
\hline \multirow{2}{*}{$\begin{array}{c}\text { Esta competência } \\
\text { depende de recursos } \\
\text { e/ou processos } \\
\text { complementares } \\
\text { para ser transferida? }\end{array}$} & Completamente & $\begin{array}{l}\text { Depende } \\
\text { bastante }\end{array}$ & Parcialmente & $\begin{array}{c}\text { Depende } \\
\text { pouco }\end{array}$ & Independente & & \\
\hline & & & $\mathrm{X}$ & & & & \\
\hline \multirow{2}{*}{$\begin{array}{l}\text { Esta competência } \\
\text { está vinculada } \\
\text { a alguma região } \\
\text { geográfica? }\end{array}$} & $\begin{array}{l}\text { Vínculo } \\
\text { total }\end{array}$ & $\begin{array}{l}\text { Vínculo } \\
\text { forte }\end{array}$ & $\begin{array}{l}\text { Vínculo } \\
\text { parcial }\end{array}$ & $\begin{array}{l}\text { Vínculo } \\
\text { fraco }\end{array}$ & $\begin{array}{l}\text { Nenhum } \\
\text { vínculo }\end{array}$ & & \\
\hline & & & & $\mathrm{X}$ & & & \\
\hline \multirow[b]{2}{*}{$\begin{array}{l}\text { Quanto tempo } \\
\text { demoraria para } \\
\text { reproduzir esta } \\
\text { competência em } \\
\text { outra parte da } \\
\text { organização? }\end{array}$} & $>5$ anos & $2-5$ anos & 6-24 meses & 1-6 meses & $<1$ mês & & \\
\hline & & & $\mathrm{X}$ & & & & \\
\hline \multirow{2}{*}{$\begin{array}{l}\text { A organização tem } \\
\text { um conhecimento } \\
\text { explícito dos } \\
\text { fatores necessários } \\
\text { para reproduzir } \\
\text { esta competência? }\end{array}$} & $\begin{array}{l}\text { De forma } \\
\text { alguma }\end{array}$ & $\begin{array}{l}\text { Muito } \\
\text { pouco }\end{array}$ & Parcialmente & $\begin{array}{c}\text { Em grande } \\
\text { parte }\end{array}$ & Completamente & & \\
\hline & & & & $\mathrm{X}$ & & & \\
\hline \multirow{2}{*}{$\begin{array}{c}\text { Resumo da } \\
\text { versatilidade }\end{array}$} & Baixa & \multicolumn{2}{|c|}{ Média } & & Alta & \multirow{2}{*}{\multicolumn{2}{|c|}{ Desconhecida }} \\
\hline & & \multicolumn{2}{|c|}{$\mathrm{X}$} & & & & \\
\hline
\end{tabular}

Uma característica do método que facilita a sua aplicação é a utilização de formulários de apoio. $\mathrm{O}$ formato dos formulários e as instruções para sua utilização foram elaborados de forma que o procedimento de análise pudesse ser autoexplicativo para os seus usuários. Essa facilidade de uso foi expressa pelos próprios gerentes durante as entrevistas de feedback, o que reforçava a avaliação da usabilidade do método.

A usabilidade também foi demonstrada durante a aplicação pelo fato de não terem surgido dificuldades geradas pela falta de entendimento do procedimento de análise. Os gerentes interpretavam facilmente as atividades que deveriam ser realizadas, embora não tivesse havido nenhum tipo de treinamento formal para a utilização do método. Mesmo que um curso de treinamento antes de iniciar o processo pudesse ter sido útil, a falta dele não foi empecilho para o bom andamento da aplicação, pois as instruções que eram fornecidas no início de cada reunião já eram suficientes para que os participantes do grupo pudessem compreender como o modelo de análise funcionava.
É importante ressaltar que os envolvidos no projeto tinham grau de instrução compatível com as habilidades requeridas para usar o método com facilidade. O modelo foi elaborado focando um público-alvo constituído de gerentes com formação superior. Portanto, pode-se afirmar que esta é uma das condições para garantir a sua usabilidade. De fato, a facilidade de uso sempre será relativa e depende basicamente do nível de seus usuários.

A utilidade do método está relacionada com a relevância de seus resultados. Do ponto de vista da empresa na qual o método foi aplicado, pode-se afirmar que ele veio suprir uma lacuna demonstrada pelos gerentes desde o primeiro contato com os pesquisadores, antes mesmo de iniciar o processo de análise. Ao final do processo, os gerentes demonstraram estar satisfeitos com os resultados que a aplicação proporcionou e sinalizaram a intenção de incorporar o método a seus processos de planejamento.

Não somente as saídas do processo de análise, mas também o processo em si, estimulava os gerentes a desenvolver uma visão que eles ainda não tinham adquirido em relação à formação de competências nas operações da academia. Desse modo, a avaliação 
positiva da utilidade do método também estaria vinculada à criação de uma nova perspectiva gerencial, orientada pela visão baseada em recursos.

Um dos fatores que influenciaram na utilidade percebida do método é, novamente, o envolvimento dos gerentes. O envolvimento dos gerentes ajudou no refinamento do modelo para que ele pudesse trazer resultados que realmente fossem relevantes para a empresa. Apesar de não ser possível garantir que a aplicação do método em outras empresas tenha o mesmo grau de utilidade que foi percebido pelos gerentes da academia de ginástica, os resultados que foram obtidos são igualmente desejados e relevantes em organizações similares. Mesmo que o método tenha utilizado um contexto particular para o seu desenvolvimento, a sua proposta é genérica para operações de serviços, ambiente no qual ele provou sua aderência.

\section{Considerações finais}

Este trabalho adotou a premissa de que é possível integrar a visão orientada pelo mercado com a visão baseada em recursos na formulação da estratégia de operações. O elemento que torna essa integração viável é o processo de identificação e análise de competências. Assim, a estratégia de operações poderá aproveitar as competências que a empresa já possui e direcionar seus processos para o desenvolvimento das competências que a empresa necessitará para competir no futuro.

Com o objetivo de contribuir para a incorporação da visão baseada em recursos na estratégia de operações de serviços, foi desenvolvido um modelo de referência composto por três etapas básicas: a) mapeamento da estratégia realizada para a identificação de competências; b) decomposição das competências identificadas em recursos-chave e em processos-chave; c) avaliação do grau de importância das competências identificadas. O teste e o refinamento do modelo seguiram a abordagem da pesquisa-ação para a aplicação em uma academia de ginástica, um típico sistema de operações de serviços.

Do ponto de vista de sua contribuição científica, o modelo proposto oferece uma alternativa para a identificação e a análise de competências e recursos estratégicos. Além de contribuir com um conjunto de técnicas para coleta e análise de dados em pesquisas descritivas e explicativas, o modelo representa uma ferramenta de gestão que pode ser utilizada pelas empresas, resultado sempre almejado pela pesquisa científica em Engenharia de Produção, notadamente uma ciência do design.

Um dos diferenciais do modelo proposto em comparação à metodologia de Mills, Platts e Bourne (2003) está relacionado ao próprio conceito de competência. $\mathrm{O}$ modelo proposto neste artigo adota a premissa de que uma competência é resultante de uma combinação de recursos e processos, relação que não está explícita na metodologia de Mills, Platts e Bourne (2003). Por esse motivo, a segunda etapa do modelo proposto (decomposição de competências) identifica, além dos recursos-chave classificados por categorias pertinentes às operações de serviços, os processos-chave que são formadores de uma competência. A identificação dos processos permite distinguir as atividades de linha de frente das atividades de retaguarda, uma peculiaridade dos sistemas de operações de serviços.

A identificação e a análise de competências e recursos da empresa estudada neste trabalho confirmaram a contribuição prática do método proposto. A sequência de três etapas do modelo (identificação, decomposição e avaliação) pôde ser aplicada com a facilidade e a rapidez que a prática empresarial demanda. Com a aplicação, os gerentes da empresa pesquisada relataram que haviam adquirido um novo olhar sobre suas operações, pois começaram a compreender, de forma simples e objetiva, o papel fundamental das competências para a estratégia da organização.

$\mathrm{Na}$ discussão dos resultados da pesquisa de campo, a factibilidade, a usabilidade e a utilidade do método proposto foram analisadas. Com base nesses critérios, foi possível concluir que o método tem uma aplicabilidade satisfatória, embora ainda seja limitado o potencial de generalização do modelo a partir de uma única aplicação.

No entanto, embora o modelo tenha sido aplicado no contexto restrito de uma academia de ginástica, a complexidade das operações de serviços é suficiente para inferir que a metodologia poderá ser aplicada com sucesso em organizações similares. As empresas que utilizarem o método proposto neste trabalho poderão reconhecer explicitamente suas competências e seus recursos estratégicos, de modo a direcionar sua estratégia para o desenvolvimento. Além de essa implicação gerar uma mudança de filosofia no processo de gestão estratégica das operações de serviços, o método sistematiza um procedimento que, quando é realizado, geralmente é feito de modo intuitivo. Dessa maneira, a formulação da estratégia de operações passa a contar com uma ferramenta adicional que permite inserir a visão baseada em recursos nesse processo.

A busca de um potencial maior de generalização sugere a continuidade da pesquisa no sentido de aplicar a metodologia em diferentes contextos de serviços e também em operações de manufatura. Recomenda-se também que sejam explorados outros aspectos contingenciais que podem influenciar na aplicabilidade do método, tais como o tamanho, a idade, a estrutura e o grau de formalização das estratégias nas empresas pesquisadas. 


\section{Referências}

ACUR, N. et al. The formalisation of manufacturing strategy and its influence on the relationship between competitive objectives, improvement goals, and action plans. International Journal of Operations \& Production Management, v. 23, n. 10, p. 1114-1141, 2003. http:// dx.doi.org/10.1108/01443570310496599

ACUR, N.; BITITCI, U. Managing strategy through business processes. Production Planning \& Control, v. 14, n. 4, p. 309-326, 2003. http://dx.doi. org/10.1080/0953728031000117977

AREND, R. J.; LÉVESQUE, M. Is the resource-based view a practical organizational theory? Organization Science, v. 21, n. 4, p. 913-930, 2010. http://dx.doi. org/10.1287/orsc.1090.0484

ARMISTEAD, C. G.; CLARK, G. Resource activity mapping: the value chain in service operations strategy. The Service Industries Journal, v. 13, n. 4, p. 221-239, 1993. http:// dx.doi.org/10.1080/02642069300000070

BARNEY, J. B.; HESTERLY, W. S. Administração estratégica e vantagem competitiva. São Paulo: Pearson Prentice Hall, 2007.

BARNEY, J. Firm resources and sustained competitive advantage. Journal of Management, v. 17, n. 1, p. 99-120, 1991. http://dx.doi. org/10.1177/014920639101700108

BOYER, K. K.; SWINK, M.; ROSENZWEIG, E. D. Operations strategy research in the POMS journal. Production and Operations Management, v. 14, n. 4, p. 442-449, 2005. http://dx.doi. org/10.1111/j.1937-5956.2005.tb00232.x

COATES, T. T.; McDERMOTT, C. M. An exploratory analysis of new competencies: a resource based view perspective. Journal of Operations Management, v. 20, n. 5, p. 435-450, 2002. http://dx.doi.org/10.1016/ S0272-6963(02)00023-2

COUGHLAN, P.; COGHLAN, D. Action research for operations management. International Journal of Operations \& Production Management, v. 22, n. 2, p. 220-240, 2002. http://dx.doi. org/10.1108/01443570210417515

EDEN, C.; HUXHAM, C. Action research for management research. British Journal of Management, v. 7, n. 1, p. 75-86, 1996. http://dx.doi. org/10.1111/j.1467-8551.1996.tb00107.x

EPPLER, M. J.; PLATTS, K. W. Visual strategizing: the systematic use of visualization in the strategicplanning process. Long Range Planning, v. 42, n. 1, p. 42-74, 2009. http://dx.doi.org/10.1016/j. lrp.2008.11.005

ESCRIG-TENA, A. B.; BOU-LLUSAR, J. C. A model for evaluating organizational competencies: an application in the context of a quality management initiative. Decision Sciences, v. 36, n. 2, p. 221-257, 2005. http://dx.doi. org/10.1111/j.1540-5414.2005.00072.x

GAGNON, S. Resource-based competition and the new operations strategy. International Journal of Operations \& Production Management, v. 19, n. 2, p. 125-138, 1999. http://dx.doi.org/10.1108/01443579910247392
GARVIN, D. A. Manufacturing strategic planning. California Management Review, v. 35, n. 4, p. 85-106, 1993.

GOLDSTEIN, S. M.; WARD, P. T. Performance effects of physicians' involvement in hospital strategic decisions. Journal of Service Research, v. 6, n. 4, p. 361-372, 2004. http://dx.doi.org/10.1177/1094670503262953

GRANT, R. M. The resource-based theory of competitive advantage: implications for strategy formulation. California Management Review, v. 33, n. 3, p.114-135, 1991.

GRUBER, M. et al. Configurations of resources and capabilities and their performance implications: an exploratory study on technology ventures. Strategic Management Journal, v. 31, n. 12, p. 1337-1356, 2010. http://dx.doi.org/10.1002/smj.865

HAYES, R. H. et al. Operations, strategy and technology: pursuing the competitive edge. New York: John Wiley \& Sons, 2005.

HAYES, R. H.; UPTON, D. M. Operations-based strategy. California Management Review, v. 40, n. 4 , p. 8-25, 1998.

HILL, T. Manufacturing strategy: text and cases. 2. ed. Burr Ridge: Irwin, 1994.

HOLMSTRÖM, J.; KETOKIVI, M.; HAMERI, A-P. Bridging practice and theory: a design science approach. Decision Sciences, v. 40, n. 1, p. 65-87, 2009. http:// dx.doi.org/10.1111/j.1540-5915.2008.00221.x

HURREERAM, D. K. Manufacturing strategy auditing for garment making companies. Benchmarking: An International Journal, v. 14, n. 3, p. 272-288, 2007.

JIA, G. Z.; BAI, M. An approach for manufacturing strategy development based on fuzzy-QFD. Computers \& Industrial Engineering, v. 60, n. 3, p. 445-454, 2011. http://dx.doi.org/10.1016/j.cie.2010.07.003

KUNC, M. H.; MORECROFT, J. D. W. Managerial decision making and firm performance under a resource-based paradigm. Strategic Management Journal, v. 31, n. 11, p.1164-1182, 2010. http://dx.doi.org/10.1002/smj.858

LEWIS, M. A. Analysing organisational competence: implications for the management of operations. International Journal of Operations \& Production Management, v. 23, n. 7, p. 731-756, 2003. http:// dx.doi.org/10.1108/01443570310481531

LEWIS, M. A. et al. Competing through operations and supply: the role of classic and extended resource-based advantage. International Journal of Operations \& Production Management, v. 30, n. 10, p. 1032-1058, 2010. http://dx.doi. org/10.1108/01443571011082517

LIMA, E. P.; COSTA, S. E. G.; FARIA, A. R. Taking operations strategy into practice: developing a process for defining priorities and performance measures. International Journal of Production Economics, v. 122, n. 1, p. 403-418, 2009. http://dx.doi.org/10.1016/j. ijpe.2009.06.022

LOWSON, R. H. The nature of an operations strategy: combining strategic decisions from the resourcebased and market-driven viewpoints. Management Decision, v. 41, n. 6, p. 538-549, 2003. http://dx.doi. org/10.1108/00251740310485181 
MILLS, J. et al. Manufacturing strategy: a pictorial representation. International Journal of Operations \& Production Management, v. 18, n. 11, p. 1067 1085, 1998. http://dx.doi.org/10.1108/01443579810231660

MILLS, J. et al. Competing through competences. Cambridge: Cambridge University Press, 2002a.

MILLS, J. et al. Creating a winning business formula. Cambridge: Cambridge University Press, 2002b.

MILLS, J.; PLATTS, K.; BOURNE, M. Applying resourcebased theory: methods, outcomes and utility for managers. International Journal of Operations \& Production Management, v. 23, n. 2, p. 148-166, 2003. http:// dx.doi.org/10.1108/01443570310458429

NIEWEGLOWSKI, R.; LIMA, E. P.; COSTA, S. E. G. Desenvolvendo um processo de análise de investimentos baseado em competências. Gestão \& Produção, v. 17, n. 2, p. 317-337, 2010. http://dx.doi.org/10.1590/ S0104-530X2010000200008

NONAKA, I. A dynamic theory of organizational knowledge creation. Organization Science, v. 5, n. 1, p. 14-37, 1994. http://dx.doi.org/10.1287/orsc.5.1.14

PANDŽA, K. et al. Evolutionary perspectives on the capability accumulation process. International Journal of Operations \& Production Management, v. 23, n. 8 , p. 822-849, 2003. http://dx.doi. org/10.1108/01443570310486310

PAPKE-SHIELDS, K. E.; MALHOTRA, M. K.; GROVER, V. Strategic manufacturing planning systems and their linkage to planning system success. Decision Sciences, v. 33, n. 1, p. 1-30, 2002. http://dx.doi. org/10.1111/j.1540-5915.2002.tb01634.x

PENG, D. X.; SCHROEDER, R. G.; SHAH, R. Linking routines to operations capabilities: a new perspective. Journal of Operations Management, v. 26, n. 6, p. 730-748, 2008. http://dx.doi.org/10.1016/j. jom.2007.11.001

PENROSE, E. T. The theory of the growth of the firm. Oxford: Basil Blackwell, 1968.

PETERAF, M. A. The cornerstones of competitive advantage: a resource-based view. Strategic Management Journal, v. 14, n. 3, p. 179-191, 1993. http://dx.doi.org/10.1002/ smj.4250140303

PLATTS, K. W. A process approach to researching manufacturing strategy. International Journal of Operations \& Production Management, v. 13, n. 8, p. $8-17$, 1993. http://dx.doi. org/10.1108/01443579310039533

PORTER, M. E. Estratégia competitiva: técnicas para análise de indústrias e da concorrência. 7. ed. Rio de Janeiro: Campus, 1991.

PORTER, M. E. What is strategy? Harvard Business Review, v. 74, n. 6, p. 61-78, 1996.

PRAHALAD, C. K.; HAMEL, G. The core competence of the corporation. Harvard Business Review, v. 68, n. 3, p. 79-91, 1990.

ROTH, A. V.; MENOR, L. J. Insights into service operations management: a research agenda. Production and
Operations Management, v. 12, n. 2, p. 145-164, 2003. http://dx.doi.org/10.1111/j.1937-5956.2003.tb00498.x

SAMPSON, S. E.; FROEHLE, C. M. Foundations and implications of a proposed unified services theory. Production and Operations Management, v. 15, n. 2, p. 329-343, 2006. http://dx.doi. org/10.1111/j.1937-5956.2006.tb00248.x

SKINNER, W. Manufacturing - missing link in corporate strategy. Harvard Business Review, v. 47, n. 3, p. $136-145,1969$.

SKINNER, W. Manufacturing strategy: the story of its evolution. Journal of Operations Management, v. 25, n. 2, p. 328-335, 2007. http://dx.doi.org/10.1016/j. jom.2006.10.008

SLACK, N. Vantagem competitiva em manufatura: atingindo competitividade nas operações industriais. São Paulo: Atlas, 1993.

SLACK, N.; LEWIS, M. Estratégia de operações. 2. ed. Bookman: Porto Alegre, 2009.

SMITH, T. M.; REECE, J. S. The relationship between strategy, fit, productivity, and business performance in a services setting. Journal of Operations Management, v. 17, n. 2, p. 145-161, 1999. http://dx.doi.org/10.1016/ S0272-6963(98)00037-0

SWAMIDASS, P. M.; DARLOW, N.; BAINES, T. Evolving forms of manufacturing strategy development: evidence and implications. International Journal of Operations \& Production Management, v. 21, n. 10 , p. 1289-1304, 2001. http://dx.doi.org/10.1108/ EUM0000000005971

VAN AKEN, J. E. Management research based on the paradigm of the design sciences: the quest for fieldtested and grounded technological rules. Journal of Management Studies, v. 41, n. 2, p. 219-246, 2004. http://dx.doi.org/10.1111/j.1467-6486.2004.00430.x

VOSS, C. A. Paradigms of manufacturing strategy re-visited. International Journal of Operations \& Production Management, v. 25, n. 12, p. 1223-1227, 2005. http:// dx.doi.org/10.1108/01443570510633620

WERNERFELT, B. A resource-based view of the firm. Strategic Management Journal, v. 5, n. 2, p.171180, 1984. http://dx.doi.org/10.1002/smj.4250050207

WONG, C. Y.; KARIA, N. Explaining the competitive advantage of logistics service providers: a resource-based view approach. International Journal of Production Economics, v. 128, n. 1, p. 51-67, 2010. http://dx.doi. org/10.1016/j.ijpe.2009.08.026

WU, S. J.; MELNYK, S. A.; FLYNN; B. B. Operational capabilities: the secret ingredient. Decision Sciences, v. 41, n. 4, p. 721-754, 2010. http://dx.doi. org/10.1111/j.1540-5915.2010.00294.x

YANG, B-C. et al. On establishing the core competency identifying model: a value-activity and process oriented approach. Industrial Management \& Data Systems, v. 106, n. 1, p. 60-80, 2006. http://dx.doi. org/10.1108/02635570610640997 